\title{
VARIAÇÕES EM TORNO DO MESMO TEMA: A DESCIDA
}

\author{
José Alonso Tôrres Freire
}

UFMS

\begin{abstract}
RESU MO
Neste artigo, será abordado o tema da descida na ficção, especialmente em obras do escritor paraense Dalcídio Jurandir, enfatizando o percurso espacial do personagem solitário do romance rumo ao (auto) conhecimento.
\end{abstract}

PALAVRAS-CHAVE

Romance. Espaço. Dalcídio Jurandir.

\section{INTRODUÇÃO}

O tema da descida na ficção, um aspecto que envolve diretamente a maneira como determinado autor utiliza o espaço em suas obras, sob a forma de variações ou figurações da viagem aos infernos, aparece freqüentemente na literatura de todos os tempos. Como afirma Ronaldo Lima Lins, em Violência e literatura, ${ }^{1}$ a partir do século XIX, período em que o romance atinge seu apogeu, a viagem recriada na literatura parecerá sempre uma descida aos infernos, tanto interior como exterior, indicando uma crescente incerteza nos homens ou talvez indiciando que o mundo, tão cheio de certezas até aquele século, estava agora recheado de insegurança e perigos ou teria se transformado no grande espaço-incógnita de que fala Ricardo Gullón. ${ }^{2}$ Northrop Frye chega mesmo a afirmar em La scritura profana que todas as narrativas literárias são complicações ou derivados metafóricos de quatro movimentos primordiais: ${ }^{3}$ 1) a queda a partir de um mundo superior; 2) a queda, a partir deste mundo, para o mundo subterrâneo; 3) a ascensão a este ou ao mundo superior a partir do mundo inferior e 4) a ascensão, a partir deste, até o mundo superior. Os dois últimos temas referentes a ascensões são comumente associados a romances convencionais, a literatura trivial de que fala Flávio R. Kothe, ${ }^{4}$ freqüentemente com finais previsíveis, pouco apropriados para uma visão realista da narrativa como se apresenta em romances do escritor paraense Dalcídio Jurandir, objeto de análise neste artigo, como veremos.

\footnotetext{
${ }^{1}$ LINS. Violência e literatura, p. 211.

${ }^{2}$ GULLÓN. Espacio e novela.

${ }^{3}$ FRYE. La escritura profana, p. 111.

${ }^{4}$ KOTHE. Literatura e sistemas intersemióticos.
} 
A obra de Dalcídio Jurandir, esse escritor quase desconhecido do grande público, apesar de sua ficção ter sido alvo de bons estudos, tais como os de Marli Teresa Furtado ${ }^{5}$ e Pedro Maligo, ${ }^{6}$ compõe-se de onze romances, entre os quais dez são de ambientação amazônica. Desses dez romances, que formam a chamada "Saga do Extremo Norte", o personagem Alfredo é uma espécie de fio condutor, com seu percurso inquieto pela cidade e pelo interior do Pará, desvelando, especialmente, o complexo espaço urbano de Belém, além de participar ou acompanhar os dramas de vários outros personagens que cruzam seu caminho.

Para os objetivos que se propõem aqui, tomo por base a concepção do espaço romanesco como aquele ambiente construído a partir dos vários discursos que sobre ele são pronunciados, tanto do narrador quanto dos personagens - o que faz com que seus significados sejam flutuantes, sempre incompletos, dependentes de cada sistema ficcional -, assim como do conflito resultante do choque dessas diferentes visões. Importantes referências teóricas a respeito podem ser encontradas em obras como as de Ricardo Gullón, ${ }^{7}$ Bachelard ${ }^{8}$ e Osman Lins, ${ }^{9}$ entre outros.

\section{ANTECEDENTES DO TEMA NA FICÇÃO}

O tema da descida ora assume a forma do mito de Orfeu, usando de suas habilidades musicais para comover os deuses infernais e conseguir recuperar Eurídice no império subterrâneo - e fracassando por ceder à curiosidade e quebrar a proibição, olhando para trás (para baixo?) -; ora assume a de Perséfone, raptada por Hades e que, voluntariamente, come os três grãos de romã - que lhe impedem de voltar ao mundo dos vivos permanentemente -; ou, ainda, no percurso que Dante empreende aos infernos, cujo portal se abre ao viajante com palavras duras e definitivas: "Deixai aqui todas as esperanças, ó vós que entrais”. Os percursos de descida, apropriados à investigação que o romance sempre empreende acerca da natureza humana, refletem não só uma sofrida busca de algo ou alguém, mas também, talvez principalmente, de si mesmo, de alguma coisa externa que reflete uma inquietação interna, como o Graal, por exemplo. De qualquer maneira, em quase todos os casos citados, é a procura de um bem perdido, com personagens ansiando por uma recuperação essencial para que se restabeleça uma situação de paz ou felicidade anteriores.

Muitas vezes a descida não se configura exatamente, ou fisicamente, como tal, variando em múltiplas versões, mas sempre implica um deslocamento - em geral forçado, ou pelo menos não de todo agradável - do personagem em busca do algo que lhe falta ou foi tomado. Dessa maneira, a trajetória de Riobaldo, em Grande sertão: veredas, para efetivar seu famoso pacto com o diabo, até as Veredas Mortas - uma encruzilhada que

\footnotetext{
${ }^{5}$ FURTADO. Universo derruído e corrosão do herói em Dalcídio Jurandir.

${ }^{6}$ MALIGO. Ruínas idílicas.

${ }^{7}$ GULLÓN. Espacio e novela.

${ }^{8}$ BACHELARD. A filosofia do não. O novo espírito científico. A poética do espaço.

${ }^{9}$ LINS. Lima Barreto e o espaço romanesco.
} 
praticamente desaparece depois do episódio -, pode ser entendida como uma descida, no sentido em que o personagem é impelido a esse encontro não só por sua vontade de se alçar à altura da chefia do bando, mas também por uma vaga noção de predestinação, e busca aí cruzar a fronteira que separa seu mundo para firmar um acordo com as forças que podem elevá-lo à condição desejada.

Por outro lado, a heroína do conto "A fuga", de Clarice Lispector, também empreende uma descida, quando decide ir embora, no sentido em que seu casamento pode ser visto como a estabilidade, a segurança, o conforto, mesmo que falte a isso tudo o amor e o sonho, e o lá fora seja o espaço-incógnita, onde ela deverá emancipar-se (reconhecer-se?); a personagem perde a oportunidade de escapar de um casamento/prisão, pois ousa olhar para trás - como Orfeu -, e sua vontade e determinação se arrefecem.

Em Dom Casmurro, é natural que Bentinho sinta-se rejeitado ao voltar para a casa da infância, descendo em direção às recordações de tempos tranqüilos e em que o amor por Capitu ainda não se transformara em um ciúme doentio. Aquele antigo locus amoenus transformara-se num espelho de sua própria consciência culpada por ter destruído o mundo de sonhos da infância, como analisa Lúcia Miguel Pereira, ${ }^{10}$ e Bentinho deixa que a casa seja demolida, numa espécie de autopunição, reproduzindoa depois, de certa maneira, purgada das lembranças, em outro bairro da cidade.

Queda significativa também protagoniza Madalena, em São Bernardo, de Graciliano Ramos, quando acredita, e declara, que a proposta de casamento que recebera era um "negócio vantajoso" para os dois, e aceita Paulo Honório, indo morar na fazenda que dá nome ao romance. Esse percurso, como se sabe, acaba em suicídio. Se ela consegue escapar da teia de posse que Paulo Honório urdiu em torno dela, o gesto não a eleva literariamente, pois ela parece optar pela saída teoricamente mais fácil (já que poderia voltar à vida simples, mas difícil, de antes) e egoísta (pois seu ato lança a tia no convívio solitário com a crueldade de Paulo Honório). A trajetória de Paulo Honório também poderia ser descrita como uma penosa ascensão seguida de queda melancólica, pois sua ambição o leva a conseguir a fazenda São Bernardo por meios escusos e, transformando a todos à sua volta em coisas manipuláveis e compráveis, abre caminho para a destruição de Madalena e a sua própria, da qual tenta recuperar sentidos por meio de sua narrativa. Aliás, esse personagem-narrador não se redime, com sua narrativa, da desgraça que causou ou sequer compreende sua responsabilidade em tudo, pois repete no próprio processo de construção da história a reificação das pessoas que ainda o rodeiam.

Uma travessia que também assume o caráter de início de uma longa descida aos infernos, que será a obsessão do personagem por um amor impossível, é a viagem de gôndola que Gustav von Aschenbach, em Morte em Veneza, de Thomas Mann, prestes a mergulhar numa busca impossível - pela beleza ou pela perfeição -, empreende ao chegar a Veneza, conduzido por um gondoleiro comparado, por Ronaldo Lima Lins, com o próprio Caronte. ${ }^{11}$

Uma descida literal é aquela de que é vítima Augusto Matraga, no conto "A hora e a vez de Augusto Matraga”, de Guimarães Rosa. Após ser surrado por vários homens em virtude de sua arrogância, valentia desmedida e crueldade, o personagem é jogado

${ }^{10}$ PEREIRA. Escritos da maturidade, p. 305.

${ }^{11}$ LINS. Violência e literatura, p. 213. 
em uma ribanceira, começando ali um longo período de sofrimento físico e mental, até conseguir reerguer-se e se redimir ao final do conto.

Descidas significativas e exemplares também são figurativizadas no percurso de dois grandes heróis bíblicos, José e Jesus Cristo, se tomarmos aqui a Bíblia no sentido literário empregado por Flávio R. Kothe em $O$ herói. ${ }^{12}$ A trajetória extremamente penosa desses dois personagens mostra, por outro lado, que nem sempre o que está embaixo é ruim, pois ambos sofrem intensa humilhação seguida de ascensão redentora.

\section{VARIAÇões da descida em ROMANCES de DalCídio JuRANDIR}

Interessante paralelo pode ser traçado entre essas descidas literárias clássicas, juntamente com sua recorrência em narrativas mais recentes, e alguns episódios de romances de Dalcídio Jurandir, não como mera recuperação de antigos mitos, mas como recursos disponíveis ao autor para figurar ou variar o tema da busca que o personagem Alfredo, o protagonista, ou o personagem mais recorrente e eixo central de nove romances, tem que realizar. Não está em discussão aqui se o autor teve ou não a intenção de projetar esses significados nos episódios analisados, mas a maneira como eles podem ser lidos, e seus sentidos possíveis no sistema da narrativa. Serão descensos associados comumente ao rebaixamento moral e à ruptura de fronteiras e hierarquias sociais, reunindo ou colocando em confronto, ainda que seja por alguns momentos, personagens de diferentes estratos, notadamente em espaços externos. Marcadas por uma busca, uma viagem ou um deslocamento pela cidade, essas inúmeras descidas aparecem com funções variadas em cada romance, e não é por mero acaso que algumas descidas aconteçam à noite, pois a noite quase sempre aparece como variação do mundo subterrâneo, causador de um medo ancestral, de acordo com afirmação de Northrop Frye, ${ }^{13}$ como acompanharemos a seguir, com exemplos de vários romances de Dalcídio Jurandir.

A primeira variação desse tema aparece já no romance Chove nos campos de Cachoeira ${ }^{14}$ em que o obcecado Eutanázio, cumprindo aí o papel de herói problemático, percorre constantemente os caminhos encharcados em busca de sentidos para uma vida aparentemente inútil, ou à procura de valores autênticos - no caso, seu amor degradado e vão por Irene. Essa bem poderia ser vista como aquela busca idólatra (para René Girard) ou demoníaca (para Lukács), conforme Lucien Goldman, ${ }^{15}$ inautêntica porque baseada em necessidade de posse, em coisificação de um ou outro dos envolvidos. Decaindo física e mentalmente pela recusa contínua da bela e impassível Irene, Eutanázio não hesita em roubar aquela que já não tem quase nada, a infeliz Felícia, a mulher que é uma espécie de saco de pancadas e usufruto de todos os homens das redondezas, e encaminhase para um anunciado e trágico fim. O próprio nome sombrio do irmão de Alfredo parece antecipar essa queda vertiginosa, essa morte antecipada e, de certo modo, provocada

\footnotetext{
${ }^{12}$ KOTHE. O herói.

${ }^{13}$ FRYE. La escritura profana.

${ }^{14}$ JURANDIR. Chove nos campos de Cachoeira.

${ }^{15}$ GOLDMAN. Sociologia do romance, p. 8-10.
} 
pela vida pregressa do personagem. Em outro romance do autor, o narrador, ao falar sobre os caminhos que levam a Cachoeira, associa o percurso de Eutanázio ao tema da descida infernal: "A partir do Salu, dois caminhos para o teso onde é propriamente Cachoeira. [...] O de baixo, roçando o catavento, é o de Eutanázio buscando Irene, a descida aos infernos [...]."16 O maior exemplo dessa peregrinação demoníaca do personagem está no capítulo XIII do romance, significativamente intitulado "Eutanázio anda".

Veremos em seguida, no romance Marajó, ${ }^{17}$ Missunga, o filho do Coronel Coutinho, voltando a um mundo do qual poderia ter se libertado, a fazenda em Marajó, para viver um percurso de dissipação dos bens do pai e atravessar, e mudar radicalmente, o caminho de três mulheres na trama, Guíta, Orminda e Alaíde. Entediado com os estudos e a vida de facilidades na cidade, ele recua - desce - ao espaço-refúgio da infância, recusando o ambiente da capital, que já não representa mais uma incógnita nem um desafio para ele. À sua maneira, o personagem representa exatamente o percurso contrário daquele que almeja Alfredo - o fascínio pelo clarão de Belém, a cidade grande e a escola, com tudo o que isso representa de libertação e emancipação. ${ }^{18}$ Tudo isso fora franqueado a Missunga sem que ele tivesse que fazer qualquer esforço nesse sentido. Um significado possível do percurso de Missunga é a anunciação, em sua trajetória, de outra descida, esta a do Coronel Coutinho e seu mundo degradado, ou a decadência e a futura queda do império do pai, já que este não terá continuadores para sua "obra”, ou, ainda, a derrota dos aventureiros e dissipadores da época áurea da borracha, da qual esse coronel é um vestígio.

Em Três casas e um rio, ${ }^{19}$ acompanharemos, com suspense crescente pelo desfecho preparado cuidadosamente pelo narrador ao longo do caminho, D. Amélia e um Alfredo deveras assustado com a estranheza do comportamento da mãe em um desses percursos perturbadores. Ambos vão em busca de uma vingança em virtude de uma antiga calúnia cuja autoria a mãe do personagem acabara de saber, depois de longo tempo amargando a vontade de tirar a limpo a maledicência, justamente num dia de festa na cidade.

$\mathrm{Na}$ intensa e longa preparação para a caminhada noite adentro, D. Amélia olhase em seu velho espelho e Alfredo compara o reflexo com "uma fera no espelho gasto", ${ }^{20}$ e se põe a divagar sobre as várias faces que ali se miraram, num movimento em que o devaneio sobre o objeto traduz uma incorporação do tempo pelo espaço:

A vaidade havia-lhe consumido o aço e em troca muitas e muitas fisionomias estavam ali acumuladas, jovens agora velhas, bonitas hoje mortas, as jovens rindo das velhas em que se transformaram e que iam ali se mirar como se quisessem reaver o rosto perdido. Estavam espiando agora D. Amélia, talvez adivinhando-lhe os sentimentos e as intenções. ${ }^{21}$

Com todas as características de uma autêntica descida, pois a busca leva mãe e filho em direção ao rio, ou seja, mais abaixo que a posição de sua casa, Dona Amélia

\footnotetext{
${ }^{16}$ JURANDIR. Ponte do Galo, p. 54.

${ }^{17}$ JURANDIR. Marajó.

${ }^{18}$ Marajó é o único romance de ambientação amazônica em que Alfredo não aparece, mas o percurso desse personagem é bem um contraponto ao de Missunga.

${ }^{19}$ JURANDIR. Três casas e um rio.

${ }^{20}$ JURANDIR. Três casas e um rio, p. 100.

${ }^{21}$ JURANDIR. Três casas e um rio, p. 101.
} 
segue resoluta em direção à vendeta, sem se importar com o fato de que seu ato pode não só afastar Alfredo definitivamente da escola, mas também fechar as portas do chalé para ela. Como o objeto da calúnia havia sido o questionamento da paternidade de Alfredo, é este que acompanha atentamente os sinais da cena de tensão que se prepara, acumulando-se ao longo do caminho sob várias formas:

O menino afundou os sapatos numa poça e sua mãe ralhou com um muxoxo contra aquela incurável distração. Ela caminhava séria, trescalante, dona daquela noite.

Nisto, súbita e ruidosa pancada de chuva, de pingos graúdos, fez debandar a pequena massa que se comprimia no trapiche.

A escuridão da noite caiu como lama sobre a chuva que crepitava no telhado gotejante, sobre as vozes dispersas dos homens, maracás, bater de pés na madeira do trapiche $[\ldots]{ }^{22}$

A lama, o domínio que D. Amélia tem da noite, a pancada de chuva que transforma o final da tarde numa noite sombria, o barulho dos maracás, além do bater de pés sobre o trapiche, tudo contribui para marcar o clima da cena, minuciosamente construído. Para essa construção cuidadosa também contribuem os retardamentos introduzidos na narração, que atrasam o desfecho e aumentam a expectativa da luta que será travada, com os dois personagens observando o desembarque do boi bumbá, os desafios entre os homens, os tambores, D. Amélia cantando uma velha música. Um desses retardamentos, absolutamente preciso pela inserção no momento exato que o transforma em motivo associado na trama, e especialmente tenso para o menino, é a recordação que Alfredo tem de uma antiga cena, quando fora até a cadeia pública para que um preso cortasse seu cabelo. Esse preso matara a ex-amante, que fora "roubada" por um comerciante, em cena que o garoto recorda ter sido descrita da seguinte maneira:

Ele (o criminoso) entrou no quarto escuro; já dentro do mosquiteiro, contemplou por algum tempo a sempre desejada e impossível amante agora adormecida e marcou bem o lugar do coração. Foi uma punhalada só. Depois, o comerciante, na outra rede, acordou ouvindo um gorgolejo no soalho. ${ }^{23}$

Essa lembrança sangrenta, ao aparecer num momento em que o personagem segue, temerosamente, sua mãe em direção à vingança, e associada à frase da mãe "ao ameaçar que ainda havia de cortar língua a alguém", ${ }^{24}$ confere à cena um caráter de antecipação de um desfecho trágico que, afinal, não acontece.

Por fim, como desfecho da longa caminhada noite adentro, da busca em longo caminho descendente naquela que talvez seja a cena mais elaborada do romance Três casas e um rio, D. Amélia desafia a autora da injúria e cospe em seu rosto: "Rápida, afastando Didico e o filho, D. Amélia avançou para a janela e cuspiu grosso e violentamente no rosto da senhora". ${ }^{25}$ Dessa maneira, a personagem coroa sua busca de vingança da calúnia que o filho sofrera e encerra de maneira vitoriosa a empreitada.

\footnotetext{
${ }^{22}$ JURANDIR. Três casas e um rio, p. 103-104.

${ }_{23}^{23}$ JURANDIR. Três casas e um rio, p. 105.

${ }^{24}$ JURANDIR. Três casas e um rio, p. 105.

${ }^{25}$ JURANDIR. Três casas e um rio, p. 128.
} 
Em Belém do Grão Pará, ${ }^{26}$ quem empreende a descida rumo ao inferno dos derrotados é a família que engorda na decadência, os Alcântaras, que são obrigados a mudar-se por causa de uma eleição perdida por seu candidato e a conseqüente perda de status e dinheiro. Esse descenso lembra aquela afirmação de Northrop Frye acerca do romance: "No começo de um romance ocorre com freqüência um descenso marcado na escala social, da riqueza à pobreza, do privilégio à luta pela sobrevivência [...]." 27 Se essa queda vertiginosa desencadeada pela política é um mau começo para Alfredo, que está iniciando sua tão desejada trajetória na cidade, o que será para ele um contratempo, e para os Alcântaras uma derrota, seguida de ostracismo, antecipação de outra maior ainda por vir, para o leitor significa que o personagem ainda tem muitos obstáculos a contornar em sua travessia urbana e que sua peregrinação só está começando.

D. Inácia Alcântara, a "madrinha-mãe", é o personagem que mais sente o amargor desse ostracismo, dessa descida forçada da família para a Rua Gentil Bittencourt, sempre a acusar o marido pela queda e a "farejar" conspirações políticas, sem perder o orgulho da antiga posição: "D. Inácia exibia as suas antigas relações com um certo gosto de olhar de frente 'aqueles canalhas' e mostrar-lhes que o lugar dela era o mesmo, embora tivesse descido para o 160 ao pé dos sapos". ${ }^{28}$ Emilinha, a filha gorda dos Alcântaras, desesperada por reaver algo do antigo fausto, praticamente obriga a família a mudar-se para uma casa em ruínas, mas localizada no bairro nobre de Nazaré, onde os ricos da cidade moram. Este novo deslocamento, no entanto, revela-se a verdadeira descida, pois ao final do romance a família é obrigada a abandonar a casa, sob vários sinais de que a queda desta é iminente: "[...] tinham que mudar naquela hora mesma. Para onde, não sabia, mas tinham. Pelo menos retirar a bagagem para a calçada, não no quintal porque, conforme desabasse, não poderiam depois atravessar o entulho". ${ }^{29}$ Nesse novo espaço de aparências da Estrada de Nazaré, seu Virgílio Alcântara, até aí um obscuro funcionário público que é afetado pela queda de seu protetor, cai ainda mais ao aceitar participar de um contrabando, enciumado pelo passado da esposa: "De repente, tudo cai. Agora, revirando os destroços do lemismo e da borracha, eis que encontra o fantasma dos acontecimentos até então despercebidos, vê as imagens de Inácia que não pudera ver e aí começa a desagregação das coisas". ${ }^{30}$ Ao aceitar a cumplicidade no recebimento de propina na Alfândega, a culpa pelo ato e os ciúmes pela mulher misturam-se na mente do personagem, dando o empurrão definitivo em seu desequilíbrio psicológico, o que vai precipitá-lo para a última queda, ao ser descoberta sua participação: "Quis então declarar o que pensava dela. Dizer-lhe tudo que pensava, destapando-se. Conteve-se, sentiu um ruir de casa dentro dele, telhas, caibros, os paredões do casarão da Alfândega, o seio de Inácia, as coxas de Inácia no incêndio e desabamento d'A Província." ${ }^{1}$

\footnotetext{
${ }^{26}$ JURANDIR. Belém do Grão Pará.

${ }^{27}$ FRYE. La escritura profana, p. 119.

${ }^{28}$ JURANDIR. Belém do Grão Pará, p. 141.

${ }^{29}$ JURANDIR. Belém do Grão Pará, p. 358.

${ }^{30}$ JURANDIR. Belém do Grão Pará, p. 273.

${ }^{31}$ JURANDIR. Belém do Grão Pará, p. 298.
} 
No romance Passagem dos inocentes, ${ }^{32}$ Alfredo muda de casa e novos dramas entram em cena, especialmente a descida que a personagem Celeste realiza rumo a um casamento sem amor e sem maiores surpresas. Inconformada com uma vida monótona em Cachoeira, Celeste esconde-se e foge em uma lancha atracada no porto, aproveitando que todos estão em uma festa, em episódio que será objeto de recordação constante da personagem. Frustrada a verdadeira fuga pretendida, vamos encontrar Celeste, neste romance, casada e com um filho, Belerofonte. Freqüentemente presa do devaneio sobre aquela fuga frustrada, fantasiando o que poderia ter sido sua vida se aquele episódio houvesse terminado de modo diferente, a personagem guarda num baú seus antigos vestidos de festa, últimos vestígios daquela época em que seus pais tinham melhores condições, e que o filho vai destruindo um a um, simbolizando com seu ato a quebra do passado e uma chamada da mãe para o presente.

Já em Primeira manha , $^{33}$ uma longa descida será acompanhada por Alfredo quase por acaso, ao encontrar, em um passeio noturno, duas vizinhas que se dirigiam à caça dos maridos, tentando confirmar traições que eles teriam cometido. Nesse longo episódio, o que acontece no decorrer é mais importante do que propriamente o desfecho, longamente mantido em suspense, retardado por um rememorar entre divertido e amargo da vida das duas mulheres, especialmente D. Abigail, a mais falante delas. Dessa forma, a trajetória em busca dos maridos traidores também se converte em desabafo com o quase desconhecido que as acompanha nesse percurso de descida: "À proporção que elas acusavam, iam se tornando vencidas, sem razão, nem esperança, enlaçadas na sedução da viagem e do que a noite consentia." ${ }^{34}$ Durante o trajeto, o narrador menciona, a certa altura, a natureza descendente dessa empresa, associada à noite, aos ruídos desconhecidos e agourentos, ou seja, ao rumo infernal do percurso empreendido por esses três solitários: "Na busca do marido, D. Abigail ia também desesperadamente curiosa dos infernos onde ele fumegava, e das rivais, não ciumenta, mas invejosa." ${ }^{35}$ Aí aparece, com toda a ambivalência, o significado da associação dos prostíbulos a "inferninhos" e se demonstra que a ida até lá, se é penosa e sofrida para mulheres que se sentem traídas, também contém certa dose de curiosidade e mistério pelo que o lugar possa apresentar em sua configuração ou por suas habitantes, especialmente se são ambientes interditos para mulheres casadas. $\mathrm{Na}$ ocasião, não é de se estranhar, como faz a amiga Ivânia, que D. Abigail fale demais sobre suas vidas, pois, nessa descida, também ocorre uma espécie de descenso social, pelo menos um momentâneo romper de fronteiras, ao abrigo da noite; e as duas mulheres deixam de ser aquelas que são "casadas da cabeça aos pés”, como afirmara o narrador anteriormente, e se transformam em pessoas comuns, desabafando sobre o que se passa na intimidade de suas casas. No entanto, a cena termina abruptamente para Alfredo sem que o leitor saiba o desfecho da busca, pois as duas o deixam para trás sem explicação, deixando entrever que caberia apenas a elas cumprirem aquela descida até o fim, mais sombria ainda pela associação com o mundo noturno, povoado de sombras e ruídos sinistros.

\footnotetext{
${ }^{32}$ JURANDIR. Passagem dos inocentes.

${ }^{33}$ JURANDIR. Primeira manhã.

${ }^{34}$ JURANDIR. Primeira manhã, p. 161.

${ }^{35}$ JURANDIR. Primeira manhã, p. 180.
} 
Nesse mesmo romance, ainda há a longa descida da sempre ausente e tão presente Luciana, que tem de cumprir uma longa e dolorosa via crucis pela suspeita de ter dado "um mau passo", significativamente libertada da prisão que os pais lhe impuseram por um raio: da associação com a intervenção divina para redimi-la da injustiça que se estava cometendo é um passo. Se, por um lado, ela só aparece no romance por meio do discurso dos outros personagens, sua presença está sempre se renovando graças à obsessão que Alfredo desenvolve por ela, o que o faz buscá-la em vários lugares da cidade, perguntando a todos que possam dar alguma informação sobre a moça amaldiçoada pelos pais. De certa maneira, Alfredo também a acompanha em sua maldição e descida, pela obsessão e pela busca que realiza, incomodado por ter à sua disposição a casa da qual Luciana fora expulsa, num paralelo entre a trajetória dessa personagem e a sua própria, humilhado que fora pelos colegas do Ginásio: ${ }^{36}$

Agora, esta casa à disposição do estudante que fugiu do estudo, à disposição do ginasiano pelo Ginásio escorraçado. Nesta casa, feita para a predileta vir morar. A anônima corre as ruas da Babilônia, moendo a sua farinha, passa os rios, não mais a tenra nem a delicada. [...] A desabençoada nunca há de pôr o pé neste soalho, nunca há de ver o mundo debruçada desta janela.

"Desabençoada" pelos pais, Luciana perdera o lugar que agora é ocupado por Alfredo e este junta mais esta obsessão às suas tantas outras buscas.

\section{REFLEXões AO FIM DO PERCURSO}

Dessa maneira, essas várias descidas, com os mais diversos objetivos e personagens, podem ser lidas como variações daquela perigosa travessia de que nos fala o personagemnarrador Riobaldo Tatarana em Grande sertão: veredas, o percurso de aprendizagem que todo ser humano tem que cumprir, uma obrigação da qual seus equivalentes ficcionais não podem escapar. Ao invés da morte bela e gloriosa dos heróis épicos (como, por exemplo, Aquiles, Pátroclo, Páris, Heitor), que almejam sair de cena no auge da força e da beleza, tendo realizado feitos que merecessem ser cantados pelos poetas que virão, de acordo com Vernant, ${ }^{37}$ o herói do romance tem que viver sua vida até o fim, muitas vezes com um desfecho que reserva um balanço nada agradável de seus feitos, como acontece com Policarpo Quaresma no último capítulo do romance de Lima Barreto. Ou seja, a trajetória desse herói romanesco, solitário e problemático, como o Alfredo de Dalcídio Jurandir, também pode ser interpretada como uma longa descida rumo ao (auto)conhecimento, uma longa e, freqüentemente, infrutífera, busca de valores autênticos num espaço degradado, uma viagem que, necessariamente, há de modificar o viajante solitário.

\section{A)}

\footnotetext{
${ }^{36}$ JURANDIR. Primeira manhã, p.117.

${ }^{37}$ VERNANT. A bela morte e o cadáver ultrajado.
} 


\section{A B STR A C T}

This article aims at analyzing the theme of the descent in the fiction of the writer Dalcídio Jurandir, specially the solitary journey of the character in the novel for the self knowledge.

\section{KEYWORDS}

Novel. Space. Dalcídio Jurandir.

\section{REFERÊNCIAS}

BACHELARD, Gaston. A filosofia do não. O novo espírito científico. A poética do espaço. Seleção de textos José Américo Motta Pessanha. Trad. Joaquim José de M. Ramos et al. São Paulo: Abril Cultural, 1978. (Coleção Os pensadores)

FRYE, Northrop. La escritura profana: un estudio sobre la estrutura del romance. Trad. Edison Simons. Barcelona: Monte Avila Editores, 1980.

FURTADO, Marlí Tereza. Universo derruído e corrosão do herói em Dalcídio Jurandir. 2002. 263 f. Tese (Doutorado). Instituto de Estudos da Linguagem/IEL, UNICAMP. Campinas, 2002.

GOLDMAN, Lucien. Sociologia do romance. Trad. Álvaro Cabral. Rio de Janeiro: Paz e Terra, 1967.

GULLÓN, Ricardo. Espacio y novela. Barcelona: Antoni Bosch, 1980. (Coleção Ensaios) JURANDIR, Dalcídio. Chove nos campos de Cachoeira. Rio de Janeiro: Vecchi, 1941. JURANDIR, Dalcídio. Marajó. 2. ed. Rio de Janeiro: Cátedra; Brasília: INL, 1978.

JURANDIR, Dalcídio. Três casas e um rio. 2. ed. Rio de Janeiro: Cátedra; Brasília: INL, 1979.

JURANDIR, Dalcídio. Belém do Grão Pará. São Paulo: Martins, 1960.

JURANDIR, Dalcídio. Passagem dos inocentes. São Paulo: Martins, 1963.

JURANDIR, Dalcídio. Primeira manhã. São Paulo: Martins, 1968.

JURANDIR, Dalcídio. Ponte do Galo. São Paulo: Martins; Rio de Janeiro: INL, 1971.

KOTHE, Flávio René. Literatura e sistemas intersemióticos. São Paulo: Cortez/Autores Associados, 1981.

KOTHE, Flávio René. O herói. São Paulo: Ática, 1985. (Série Princípios)

LINS, Osman. Lima Barreto e o espaço romanesco. São Paulo: Ática, 1976. (Coleção Ensaios). LINS, Ronaldo Lima. Violência e literatura. Rio de Janeiro: Tempo Brasileiro, 1990.

MALIGO, Pedro. Ruínas idílicas: a realidade amazônica de Dalcídio Jurandir. Revista USP, São Paulo, n. 13, p. 48-57, março/maio, 1992.

PEREIRA, Lucia Miguel. Escritos da maturidade: seleta de textos publicados em periódicos (1944 -1959). Pesquisa bibliográfica, seleção e notas de Luciana Viegas. Rio de Janeiro: Graphia Editorial, 1994. (Série Revisões)

VERNANT, Jean-Pierre. A bela morte e o cadáver ultrajado. Discurso, FFLCH/USP, São Paulo, n. 9, p. 31-62, 1978. 